\title{
The incidence of environmental regulation in a developing economy with sector-specific unemployment: a note
}

\author{
Leonard F.S. Wang ${ }^{*} \bullet$ Ya-Chin Wang ${ }^{2} \cdot$ Lihong Zhao $^{3}$ \\ ${ }^{1}$ Department of Applied Economics, National University of Kaohsiung, Taiwan \\ ${ }^{2}$ Department of Finance and Banking, Kun Shan University, Taiwan \\ ${ }^{3}$ China HuanQiu Contracting \& Engineering Corporation, Beijing, China
}

\begin{abstract}
This note investigates the effects of environmental regulation in a general-equilibrium model incorporating capital mobility and sector-specific unemployment. The government sets a maximum allowable level of environmental use in advance. This environmental use beneficially affects the production, but causes negative externality which is restricted by a regulating function. It specifically examines the effects of environmental regulation on output levels, factor returns, urban unemployment ratio, the incidence issue and the national income. Our analysis reveals that the trade-off relationship between environment and economic development is likely to exist.
\end{abstract}

Keywords: environmental regulation, unemployment, general equilibrium, developing economy

JEL Classification Codes: D50, J64, Q28

\section{Introduction}

It is well known that many developing economies, such as the fast-growing Chinese economy, have been being significantly environment-intensive. Along with the wave of market reforms, concerns over this phenomenon have been prominent in public discussions and in the meanwhile, much debate about the relative merits of environment and economic growth has been witnessed. Needless to say, we can not consider all possible sources to reduce the environmental intensity. ${ }^{1}$ Rather, our attention is focused

*Corresponding author. E-mail: lfswang@nuk.edu.tw.

Citation: Wang, L.F.S., Wang, Y.-C. and Zhao, L. (2012) The incidence of environmental regulation in a developing economy with sector-specific unemployment: a note, Economics and Business Letters, 1(1), 3-11.

${ }^{1}$ Technological improvement and structural adjustment are also the factors to reduce this intensity. 
on the environmental regulation, for example, more restricted licensing requirements for access to energy. Since the 1990's, more governments have recognized and owed the worsening environmental quality to the failure of environment regulation. We want to explore the issue whether environmental regulation in a developing economy is helping or hindering the economic growth.

Governments may conduct environmental regulation by imposing taxes and proceeds to clean up company-generated pollution. However, it is more direct for a government to set up an environmental standard to limit the pollution. Consequently, firms in such an industry will develop a series of pollution purification process to have the standards met so that the environment can be protected. On the other hand, although the literature about this area in partial equilibrium is quite enormous, ${ }^{2}$ little attention has been paid to general-equilibrium scenario. Wang (1990) examined the backward incidence of pollution control within the context of the Harris and Todaro (1970) economy. Rapanos (1992) argued that "the theory of externalities has gained new life recently, primarily because of the increasing concerns for environmental problems (p.226)" and provided an analysis on production externality and taxation. Beladi and Frasca (1999) extended Wang's (1990) model by including an urban non-polluting sector, and Daitoh (2003) argued that a rise in the pollution tax rate in the urban manufacturing has spillover effect on the two labor market distortion which will provide sufficient conditions for the welfare-improving environmental policy reform in the Harris-Todaro economy. Recently, Rapanos (2007) followed Wang's (1990) model but considered the case of a production-production externality with the urban sector emitting a negative externality on the agriculture sector. Fullerton and Heutel (2007) explored the distributional effects of a pollution tax considering general forms of substitution.

Quantitative regulation may be much more prevalent in a not-so-regular economy, especially in developing economies, for sake of political and administrative reasons. ${ }^{3}$ Bommer and Schulze (1999) did not take taxes into account and regarded the environment as an additional input in a full-employment model, and explored the effects of environmental quantitative restriction within a sector-specific capital model. Nonetheless, in the real world, many developing economies are still suffering from unemployment due to the uneven development between the rural and the urban. In a pioneering literature, Harris and Todaro (1970) depicted a two-sector model involving urban unemployment, which has received considerable attention in economic research. It is evidenced by the applications of this model to imported technologies by Batra and Lahiri (1987), to the incidence of pollution control by Wang (1990), and to the partial privatization by Beladi and Chao (2006a).

Unlike Fullerton and Heutel (2007) who examined the distributional effects of pollution tax, the purpose of this note is to study the effects of environmental regulation in a two-sector general-equilibrium framework with sector-specific unemployment. The government sets a maximum allowable level of environmental use in advance. This environmental use beneficially affects the production, but causes negative externality which is restricted by a regulating function. We define an elasticity of the environmental externality and introduce sector-specific unemployment. Since capital mobility is often claimed to be associated with economic liberalization, capital is considered to be perfectly mobile intersectorally in our model.

\footnotetext{
${ }^{2}$ See, for example, Simpson (1995), Carlsson (2000), Ohori (2006) and Bárcena-Ruiz and Garzón (2002, 2006).

${ }^{3}$ See Buchanan and Tullock (1975) for discussions.
} 
The remainder of this paper is organized as follows. Section 2 systematically establishes the formal model. Section 3 explores the comparative statics analysis and gives economic explanations. Concluding remarks are drawn in section 4.

\section{The Model}

We consider a developing economy consisting of two sectors: the urban (indexed by $X$ ) and the rural (indexed by $Y$ ). The urban sector produces a manufactured good $(\operatorname{good} X)$, while the rural sector produces an agricultural good $(\operatorname{good} Y)$. The production of each good utilizes labor $(L)$ and capital $(K)$, both of which are perfectly mobile between sectors.

The urban sector uses the environment as an additional input. It assumes that the use of environment increases the productivity of manufacturing production. As in Bommer and Schulze (1999), the operation of environment involves negative externality and has to be restricted by a continuous function which reflects the externality of environment. In what follows, let $E_{M}$ be the maximum use of environment by firms. When polluting industries use the environment to the maximum, $E=E_{M}$. Therefore, the production function of manufactured good is given by:

$$
X=g(E) F_{X}\left(K_{X}, L_{X}\right)
$$

where $F_{X}$ is a linearly homogeneous function in capital and labor, $K_{i}$ and $L_{i}$ are the capital and labor employed in sector $i(i=X, Y)$, respectively. We can define the elasticity of environmental externality on production as:

$$
e=\frac{d g}{d E} \frac{E}{g}
$$

The assumption that the use of environment increases the productivity of manufacturing production and the negative externality ensures that $0<e<1$. For instance, an increase in $E$ by, say, 10 percent increases the output level of manufactured good by less than 10 percent because the productivity at the final process of production employs the most of environment, which explains why the use of environment increases the productivity at a decreasing rate.

The production function of agricultural good is written as:

$$
Y=F_{Y}\left(K_{Y}, L_{Y}\right)
$$

where $F_{Y}$ is also a linearly homogeneous function in capital and labor.

Perfect competition is assumed to prevail in both sectors and the price of agricultural good is chosen as the numeraire. Accordingly, in equilibrium, the zero-profit conditions can be described as:

$$
\begin{gathered}
w_{X} L_{X}+r K_{X}=\operatorname{Pg}(E) F_{X}\left(K_{X}, L_{X}\right) \\
w_{Y} L_{Y}+r K_{Y}=F_{Y}\left(K_{Y}, L_{Y}\right)
\end{gathered}
$$


where $w_{i}$ is the wage rate in sector $i, r$ is the capital rental, and $P$ is the relative price of manufactured good.

Sector-specific unemployment is introduced into the urban sector. According to Harris and Todaro (1970), the urban wage is set exogenously above the market-clearing wage. This scheme induces the rural labor to move to the urban region until the expected urban wage equals the actual rural wage:

$$
w_{X} /(1+\mu)=w_{Y}
$$

where $\mu$ is the urban unemployment ratio.

We specify the equilibrium conditions for the factor markets:

$$
\begin{gathered}
(1+\mu) L_{X}+L_{Y}=\bar{L} \\
K_{X}+K_{Y}=\bar{K}
\end{gathered}
$$

where $\bar{L}$ and $\bar{K}$ are the endowments of labor and capital in the economy, respectively.

Now, turn to the demand side of the economy. Assuming homothetic preferences, the commodity-market equilibrium is:

$$
\hat{X}-\hat{Y}=-\sigma_{D} \hat{P}
$$

where $\sigma_{D}$ is the elasticity of substitution between goods $X$ and $Y$. Here and throughout this paper, a hat over a variable indicates the proportional change (e.g. $\hat{P} \equiv d P / P$ ).

\section{Effects of Environmental Regulation}

We begin the analysis with some preparatory work. Let $\lambda_{K i} \equiv K_{i} / \bar{K}$ and $\lambda_{L i} \equiv L_{i} / \bar{L}$ be the fractions of factors that are employed in the sector $i(i=X, Y)$. Let also $\theta_{K i} \equiv r K_{i} / I_{i}$ and $\theta_{L i} \equiv w L_{i} / I_{i}$ be the distributive shares of factors employed in the sector $i$, where $I_{i}=w_{i} L_{i}+r K_{i}$ represents the income in the sector $i$. It is also noteworthy that $(1+\mu) \lambda_{L X}+\lambda_{L Y}=1, \lambda_{K X}+\lambda_{K Y}=1$ and $\theta_{K i}+\theta_{L i}=1$. As proved by Neary (1981 and 1988), $\lambda_{K X} \lambda_{L Y}-(1+\mu) \lambda_{L X} \lambda_{K Y}$ must be positive for the system stability, suggesting that the manufactured good is relatively capital intensive. Considering the production can substitute between factors in response to the change in factor returns, we define the elasticities of substitution between factors in both sectors:

$$
\begin{gathered}
\hat{L}_{X}-\hat{K}_{X}=\sigma_{X} \hat{r} \\
\hat{L}_{Y}-\hat{K}_{Y}=-\sigma_{Y}\left(\hat{w}_{Y}-\hat{r}\right)
\end{gathered}
$$

where $\sigma_{i}$ is the elasticity of substitution between factors sector $i$. 
The completed model can now be used to explore the effects of environmental deregulation. Totally differentiating equations (1), (3), (4), (5), (7) and (8), we can derive the following relationships:

$$
\begin{gathered}
\hat{X}=\theta_{L X} \hat{L}_{X}+\theta_{K X} \hat{K}_{X}+e \hat{E} \\
\hat{Y}=\theta_{L Y} \hat{L}_{Y}+\theta_{K Y} \hat{K}_{Y} \\
\theta_{K X} \hat{r}=\hat{P}+e \hat{E} \\
\theta_{L Y} \hat{w}_{Y}+\theta_{K Y} \hat{r}=0 \\
(1+\mu) \lambda_{L X} \hat{L}_{X}+\mu \lambda_{L X} \hat{\mu}+\lambda_{L Y} \hat{L}_{Y}=0 \\
\lambda_{K X} \hat{K}_{X}+\lambda_{K Y} \hat{K}_{Y}=0
\end{gathered}
$$

Substitute equations (10) and (11) into equations (1a) and (3a) to obtain:

$$
\begin{aligned}
& \hat{L}_{X}=\hat{X}+\theta_{K X} \sigma_{X} \hat{r}-e \hat{E} \\
& \hat{L}_{Y}=\hat{Y}-\theta_{K Y} \sigma_{Y}\left(\hat{w}_{Y}-\hat{r}\right) \\
& \hat{K}_{X}=\hat{X}-\theta_{L X} \sigma_{X} \hat{r}-e \hat{E} \\
& \hat{K}_{Y}=\hat{Y}+\theta_{L Y} \sigma_{Y}\left(\hat{w}_{Y}-\hat{r}\right)
\end{aligned}
$$

Making use of these four equations, equations (7a) and (8a) yield that:

$$
\begin{gathered}
(1+\mu) \lambda_{L X} \hat{X}+\lambda_{L Y} \hat{Y}=-B \hat{r}+\left[(1+\mu) \lambda_{L X}+\lambda_{L Y} \theta_{K Y} \sigma_{Y}\right] \hat{w}_{Y}+(1+\mu) \lambda_{L X} e \hat{E} \\
\lambda_{K X} \hat{X}+\lambda_{K Y} \hat{Y}=A \hat{r}-\lambda_{K Y} \theta_{L Y} \sigma_{Y} \hat{w}_{Y}+\lambda_{K X} e \hat{E}
\end{gathered}
$$

where $A=\lambda_{K X} \theta_{L X} \sigma_{X}+\lambda_{K Y} \theta_{L Y} \sigma_{Y}$ and $B=(1+\mu) \lambda_{L X} \theta_{K X} \sigma_{X}+\lambda_{L Y} \theta_{K Y} \sigma_{Y}$.

Combining equations (12) and (13), we have:

$$
C \hat{X}=\left(A \lambda_{L Y}+B \lambda_{K Y}\right) \hat{r}-\left[(1+\mu) \lambda_{L X}+\lambda_{L Y} \sigma_{Y}\right] \lambda_{K Y} \hat{w}_{Y}+C e \hat{E}
$$

where $C=\lambda_{K X} \lambda_{L Y}-(1+\mu) \lambda_{L X} \lambda_{K Y}>0$. Viewing equation (5a), equation (14) reduces to:

$$
C \hat{X}-D \hat{r}=C e \hat{E}
$$

where $D=A \lambda_{L Y}+B \lambda_{K Y}+\left[(1+\mu) \lambda_{L X}+\lambda_{L Y} \sigma_{Y}\right] \lambda_{K Y} \theta_{K Y} / \theta_{L Y}>0$. Solving equations (9), (4a), (5a) and (12) leads to:

$$
\hat{X}+M \hat{r}=N e \hat{E}
$$


where

$$
M=B+\lambda_{L Y} \theta_{K X} \sigma_{D}+\left[(1+\mu) \lambda_{L X}+\lambda_{L Y} \theta_{K Y} \sigma_{Y}\right] \theta_{K Y} / \theta_{L Y}>0
$$

and

$N=(1+\mu) \lambda_{L X}+\lambda_{L Y} \sigma_{D}$. Following Neary (1978), a sufficient condition for system stability is $0<\sigma_{D} \leq 1$ and thus $0<N \leq 1$.

As a result of equations (14a) and (15), we can obtain the effects of environmental regulation on the output level of manufactured good and on the capital rental:

$$
\begin{gathered}
\hat{X} / \hat{E}=(C M+N D) e / \Delta>0 \\
\hat{r} / \hat{E}=C e(N-1) / \Delta \leq 0
\end{gathered}
$$

where $\Delta=C M+D>0$. Equations (16) and (17) show that $\hat{E}$ moves along with $\hat{X}$ but against $\hat{r}$. Not surprisingly, when the government programs to reduce total emissions, i.e. $\hat{E}<0$, it decreases the output level of manufactured good and leads to a higher capital rental.

Perhaps equation (17) appears counter-intuitive. In the absence of the environment serving as the additional input, the capital released by the decreased output level of manufactured good can be absorbed by the agricultural sector only if its return decreases. In this model, environmental regulation propels the manufacturing sector to rely more on capital, exerting a positive impact on its return. The impact from primary change in the additional input dominants the one from the induced result, i.e. equation (16). Accordingly, the result in equation (17) holds.

Following the above interpretation, it is straightforward to observe that it decreases the rural wage:

$$
\hat{w}_{Y} / \hat{E}=-\left(\theta_{K Y} / \theta_{L Y}\right)(\hat{r} / \hat{E}) \geq 0
$$

The incidence of environmental regulation on factor returns can be obtained from equations (17) and (18):

$$
\left(\hat{w}_{Y}-\hat{r}\right) / \hat{E} \geq 0
$$

showing the labor in the rural sector bears relatively more of the burden of environmental regulation than does the capital. Therefore, it attracts the rural labor to the urban sector, which leads to an increase in the urban unemployment ratio:

$$
\hat{\mu} / \hat{E}=-[(1+\mu) / \mu]\left(\hat{w}_{Y} / \hat{E}\right) \leq 0
$$

The incidence of environmental regulation on output levels can be obtained from equations (4a) and (9):

$$
\begin{gathered}
(\hat{X}-\hat{Y}) / \hat{E}=\sigma_{D} e-\theta_{K X} \sigma_{D}(\hat{r} / \hat{E})>0 \\
\hat{P} / \hat{E}=-\left(1 / \sigma_{D}\right)[(\hat{X}-\hat{Y}) / \hat{E}]<0
\end{gathered}
$$


Therefore, environmental regulation leads to a decrease in the output level of manufactured good in the relative sense and thus an increase in its price. ${ }^{4}$

In sum, we can obtain the following proposition:

Proposition 1. For a developing economy with sector-specific unemployment, environmental regulation actually lowers the output level of manufactured good absolutely and relatively and thereby promotes its price. In addition, environment regulation results in higher capital return and lower rural wage. These results negatively impact on the urban unemployment ratio.

Finally, we examine the effect of environmental regulation on national income, which is expressed as $I=w_{X} L_{X}+w_{Y} L_{Y}+r \bar{K}=w_{Y} \bar{L}+r \bar{K}$. Differentiating $I$ with respect to $E$ and using (5a) give that:

$$
\hat{I} / \hat{E}=\theta_{L}\left(\hat{w}_{Y} / \hat{E}\right)+\theta_{K}(\hat{r} / \hat{E})=\left[\left(\theta_{K} \theta_{L Y}-\theta_{L} \theta_{K Y}\right) / \theta_{L Y}\right](\hat{r} / \hat{E})
$$

where $\theta_{L}\left(=w_{Y} \bar{L} / I\right)$ and $\theta_{K}(=r \bar{K} / I)$ are the shares of labor and capital returns in national income, respectively. Therefore,

$$
\hat{I} / \hat{E}>(<) 0 \text { provided } \theta_{K} \theta_{L Y}-\theta_{L} \theta_{K Y}<(>) 0
$$

For, $\theta_{K} \theta_{L Y}-\theta_{L} \theta_{K Y}<0$ environmental regulation decreases national income. Conversely, for $\theta_{K} \theta_{L Y}-\theta_{L} \theta_{K Y}>0$, environmental deregulation may paradoxically lower the national income.

Therefore, we can obtain the following proposition:

Proposition 2. For a developing economy with sector-specific unemployment, environmental deregulation will not necessarily increase the national income, reflecting the trade-off relationship between environment and economic growth.

\section{Concluding Remarks}

In this paper, we have elaborated on the models of Rapanos $(1992,2007)$ and Bommer and Schulze (1999) in the Harris-Todaro general-equilibrium model. As usual in such models, the urban sector is capital intensive for the system stability. We examine the effects of environmental regulation upon the economy in a general equilibrium, competitive framework. The effects of deregulation can be easily obtained from those opposite to regulation.

This paper sheds light in several aspects of the environmental regulation in the developing economy. It is shown that in the Harris-Todaro economy environmental regulation lowers the output level of manufactured good absolutely and relatively and thereby promotes its price. In addition, environment regulation results in higher capital return and lower rural wage. These results negatively impact on the urban unemployment ratio. However, environmental deregulation will not necessarily increase

\footnotetext{
${ }^{4}$ It has been proved in Beladi and Chao (2006b) that the rural-urban migration occurs due to the increase in the price of the manufactured good, thereby increasing the urban unemployment ratio.
} 
the national income, which reflects the trade-off relationship between environment and economic growth.

It is clear that there are some directions deserving future study. First, this note does not deal with a mixed oligopolistic market. In many developing economies, state-owned enterprises often play an important role. Beladi and Chao (2006a) and Chao et al. (2006) investigated the effects of partial privatization in a developing economy. This extension will be an effort to reflect the characteristics of a developing economy more accurately. Second, policy instruments, such as taxation, are usually employed by the government. Beladi and Chao (2006b) investigated the effects of pollution taxation in a Harris-Todaro economy. Therefore, it will be fruitful to address how the policy instrument rationalizes subsequent discussions in our model.

\section{Acknowledgements}

We would like to thank Francisco J. Delgado and the anonymous referee for their useful comments and review of the manuscript. Any errors or omissions are the authors' responsibility.

\section{References}

Bárcena-Ruiz, J.C. and Garzón, M.B. (2002) Environmental taxes and strategic delegation, Spanish Economic Review, 4, 301-310.

Bárcena-Ruiz, J.C. and Garzón, M.B. (2006) Mixed oligopoly and environmental policy, Spanish Economic Review, 8, 139-160.

Batra, R.N. and Lahiri, S. (1987) Imported technologies, urban unemployment and the North-South dialogue, Journal of Development Economics 25, 21-32.

Beladi, H. and Chao, C.-C. (2006a) Mixed ownership, unemployment, and welfare for a developing economy, Review of Development Economics, 10, 604-611.

Beladi, H. and Chao, C.-C. (2006b) Environmental policy, comparative advantage, and welfare for a developing economy, Environment and Development Economics, 11, 559-568.

Beladi, H. and Frasca, R. (1999) Pollution control under an urban binding minimum wage, Annals of Regional Science, 33, 523-533.

Bommer, R. and G.G. Schulze (1999) Environmental improvement with trade liberalization, European Journal of Political Economy, 15, 639-661.

Buchanan, J. and Tullock, G. (1975) Polluters' profits and political response: direct control versus taxes, American Economic Review, 65, 139-147.

Carlsson, F. (2000) Environmental taxation and strategic commitment in duopoly models, Environmental and Resource Economics, 15, 243-256.

Chao, C.C., Hazari, B. and Yu, E.H.S. (2006) Rising wage inequality in developing economies: privatization and competition, Journal of International Trade and Economic Development, 15, 375-385.

Daitoh, I. (2003) Environmental protection and urban unemployment: environmental policy reform in a polluted dualistic economy, Review of Development Economics, 7, 496-509.

Fullerton, D. and Heutel, G. (2007) The general equilibrium incidence of environmental taxes, Journal of Public Economics, 91, 571-591.

Harris, J.R. and Todaro, M. (1970) Migration, unemployment and development: a twosector analysis, American Economic Review, 60, 126-142. 
Neary, J.P. (1978) Dynamic stability and the theory of factor-market distortions, American Economic Review, 88, 671-682.

Neary, J.P. (1981) On the Harris-Todaro model with intersectoral capital mobility, Economica, 48, 219-234.

Neary, J.P. (1988) Stability of the mobile-capital Harris-Todaro model: some further results, Economica, 55, 123-127.

Ohori, S. (2006) Optimal environmental tax and level of privatization in an international duopoly, Journal of Regulatory Economics, 29, 225-233.

Rapanos, V.T. (1992) A note on externalities and taxation, Canadian Journal of Economics, 25, 226-232.

Rapanos, V.T. (2007) Environmental taxation in a dualistic economy, Environment and Development Economics, 12, 73-89.

Simpson, R.D. (1995) Optimal pollution taxation in a Cournot duopoly, Environmental and Resource Economics, 6, 359-369.

Wang, L.F.S. (1990) Unemployment and the backward incidence of pollution control, Journal of Environmental Economics and Management, 18, 292-298. 